Nat. Hazards Earth Syst. Sci., 12, 2719-2729, 201
www.nat-hazards-earth-syst-sci.net/12/2719/2012
doi:10.5194/nhess-12-2719-2012
( Author(s) 2012. CC Attribution 3.0 License.

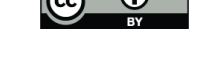

\author{
(1)
}

-

\title{
Rainfall and earthquake-induced landslide susceptibility assessment using GIS and Artificial Neural Network
}

\author{
Y. Li ${ }^{1}$, G. Chen ${ }^{1}$, C. Tang ${ }^{2}$, G. Zhou ${ }^{3}$, and L. Zheng ${ }^{1}$ \\ ${ }^{1}$ Department of Civil and Structural Engineering, Kyushu University, Fukuoka, Japan \\ ${ }^{2}$ State Key Laboratory of Geo-Hazard Prevention, Chengdu University of Technology, Chengdu, China \\ ${ }^{3}$ Nishi-Nippon Institute of Technology, Fukuoka, Japan \\ Correspondence to: Y. Li (liyange1984@gmail.com)
}

Received: 14 July 2011 - Revised: 10 July 2012 - Accepted: 18 July 2012 - Published: 31 August 2012

\begin{abstract}
A GIS-based method for the assessment of landslide susceptibility in a selected area of Qingchuan County in China is proposed by using the back-propagation Artificial Neural Network model (ANN). Landslide inventory was derived from field investigation and aerial photo interpretation. 473 landslides occurred before the Wenchuan earthquake (which were thought as rainfall-induced landslides (RIL) in this study), and 885 earthquake-induced landslides (EIL) were recorded into the landslide inventory map. To understand the different impacts of rainfall and earthquake on landslide occurrence, we first compared the variations between landslide spatial distribution and conditioning factors. Then, we compared the weight variation of each conditioning factor derived by adjusting ANN structure and factors combination respectively. Last, the weight of each factor derived from the best prediction model was applied to the entire study area to produce landslide susceptibility maps.

Results show that slope gradient has the highest weight for landslide susceptibility mapping for both RIL and EIL. The RIL model built with four different factors (slope gradient, elevation, slope height and distance to the stream) shows the best success rate of $93 \%$; the EIL model built with five different factors (slope gradient, elevation, slope height, distance to the stream and distance to the fault) has the best success rate of $98 \%$. Furthermore, the EIL data was used to verify the RIL model and the success rate is $92 \%$; the RIL data was used to verify the EIL model and the success rate is $53 \%$.
\end{abstract}

\section{Introduction}

The 12 May 2008 Wenchuan earthquake, with the characteristics of high magnitude $\left(M_{\mathrm{s}}=8.0\right)$, shallow hypocenter (the depth of the hypocenter was less than $20 \mathrm{~km}$ ), long fracture zone (approximately $300 \mathrm{~km}$ ), great rupture (the largest rupture was about $7 \mathrm{~m}$ ), large energy release (three times that of the 1976 Tangshan earthquake) and long duration (the main shock duration was about $120 \mathrm{~s}$ ) (Xu et al., 2011), triggered as many as 56000 landslides of various types in the mountainous terrain in Sichuan Province, China, throughout an area of about $50000 \mathrm{~km}^{2}$. According to statistical data, the earthquake destroyed 5362500 buildings, left about 4.8 million people homeless and about 20000 people immediately dead (Tang et al., 2011). It was the deadliest earthquake to hit China since the 1976 Tangshan earthquake, when 240000 people died. The most affected area of the huge earthquake extended from Wenchuan County to the north and east, along the main faults in Longmenshan. The hardest hit regions were Wenchuan, Beichuan, Qingchuan, Mao xian, An xian, Dujiangyan, Pingwu and Pengzhou.

Landslide susceptibility assessment is an important tool for land use planning and special development activity within a given area, which is based on past landslides, geology, topography, hydrology and other pertinent data. It is widely performed in two steps. The first one is the construction of a landslide inventory map providing the spatial distribution of existing landslides that can be derived from field survey, air photo interpretation and literature search (Wieczorek, 1984). The second step is the preparation of a landslide susceptibility map showing the "likelihood that a phenomenon will occur in an area on the basis of the local terrain conditions" 
(Soeters and van Westen, 1996). There have been many studies of landslide susceptibility assessment (Soeters and van Westen, 1996; Guzzetti et al., 2005; Lee and Evangelista, 2006; Conoscenti et al., 2008; van Westen et al., 2008; Bai et al., 2010). These methods can be classified into two broad categories: qualitative and quantitative. With the development of computer and geographic information system (GIS) technology, quantitative methods have been becoming more popular than qualitative methods in the last few decades (van Westen et al., 2006). Statistical analysis and Artificial Neural Network (ANN) have been widely used in various quantitative hazard assessments (Leonardo et al., 2005; Ermini et al., 2005; Lee and Evangelista, 2006; Pradhan et al., 2010). With the neural network method, Nefesilioglu et al. (2008) showed that ANN gives a more optimistic evaluation of landslide susceptibility than logistic regression analysis. Ermini et al. (2005) compared two neural architectures (probabilistic neural network and multi-layered perceptor) and obtained a better prediction result. Kanungo et al. (2006) showed that a landslide susceptibility map derived from combined neural and fuzzy weighting procedure is the best amongst the other weighting techniques. In more practical terms, neural network is a non-linear statistical data model or decisionmaking tool, and can receive high prediction accuracy for classification problem, especially for large amount samples.

It is known that factors for initiating landslides can be broadly classified into conditioning and triggering factors. Common triggering factors include earthquakes and rainfall. For rainfall-induced landslide (RIL), many researchers have focused on the rainfall conditions that lead to slope failure (Glade et al., 2000; Lin et al., 2006; Dahal and Hasegawa, 2008). For earthquake-induced landslide (EIL), previous studies are mainly focused on (1) identification and description of coseismic landslides; (2) relationship between earthquakes, especially catastrophic ones, and landslides (for example, Keefer, 2000; Qi et al., 2010; Ayalew et al., 2011). Meanwhile, there has also been some research about rainfall or earthquake-induced landslide susceptibility assessment (Guzzetti et al., 2005; Crozier, 2005; Lee et al., 2008; Kamp et al., 2008). Since these two kinds of landslides are likely to differ in terms of mechanics and dynamics (Crozier, 2005; Chang et al., 2007), for a given area where landslides can be triggered by both rainfall and earthquake such as Sichuan Province, it is important to model both of these two kinds of landslides.

In this study, we choose Qingchuan County, Sichuan Province, as the study area. Our objective is to compare the difference between the landslides triggered by rainfall and the ones by the 12 May 2008 Wenchuan earthquake. We attempt to resolve this problem not just by comparing the variation between landslide spatial distribution and conditioning factors, but also comparing the variation of the weight of each conditioning factor in the ANN prediction models.

\section{Study area and data source}

\subsection{Study area}

Qingchuan County (Fig. 1) is located at $32^{\circ} 12^{\prime}$ to $32^{\circ} 56^{\prime} \mathrm{N}$, $104^{\circ} 36^{\prime}$ to $105^{\circ} 38^{\prime} \mathrm{E}$, covering an area of $3271 \mathrm{~km}^{2}$. It is to the north-east of the earthquake's epicenter and $250 \mathrm{~km}$ away from the northern part of Chengdu. The area was selected because of its moderate-high seismic activity (as shown in Fig. 1; VI-XI represent the earthquake magnitude contours). 78 aftershocks occurred in the area, three exceeding magnitude 6 , with a maximum of 6.4 .

The tectonics and geological settings in the area are very complex. There is a wide variety of sedimentary (limestones, sandstones and conglomerates), magmatic (granite) and metamorphic rocks (shales, schists, gneiss) from Cambrian to Jurassic age; Quaternary loess unconsolidated sedimentary deposits widely outcrop. Two main active faults cross the area: the Pingwu-Qingchuan fault (F1); and the Yingxiu-Beichuan fault (F2), which belongs to Longmenshan fault belt, is a thrust fault $60^{\circ}-70^{\circ} \mathrm{NW}$ dipping. Qingchuan County is situated in the transitional belt between the Sichuan Basin and the western Sichuan Plateau, a mainly mountainous area with northwestern part characterized by higher elevation than the southeastern one. The elevations in the northwestern part are generally $1800-3800 \mathrm{~m}$ above mean sea level; the central part is characterized by a medium relief landscape with a generally elevation of 1200-1800 m; and the elevations in the southeastern part are generally between 490 and $1200 \mathrm{~m}$ high. Slope gradient reaches a maximum of about $80^{\circ}$, with a mean value of $38^{\circ}$.

The region is drained by the Bailong, Qingzhu and Qiaozhuang Rivers. These three rivers flow very rapidly with discharges of approximately 525, 30, and $40 \mathrm{~m}^{3} \mathrm{~s}^{-1}$ respectively. Besides, Qingchuan County has a sub-tropical and monsoon climate and the annual average temperature is about $13.7^{\circ} \mathrm{C}$. The annual average precipitation is $1021.7 \mathrm{~mm}$, and the highest annual precipitation of $1780 \mathrm{~mm}$ occurred in $1961.80 \%$ of annual precipitation is mostly concentrated in the period from June to September, and the highest amount of $90 \%$ occurred in 1981.

\subsection{Data source}

The basic data utilized in the study include (1) a grid digital elevation model (DEM), which was made through the interpolation of contour lines from available topographic map; (2) a geological map collected from the China Geological Surveying; (3) selected aerial photographs taken by Ministry of Land and Resources after the Wenchuan earthquake.

Landslide inventory mapping is the systematic mapping of existing landslides in a region using different techniques such as field survey, air photo interpretation, and literature search for historical landslide records (Wieczorek, 1984). According to the landslide inventory mapping of this study 


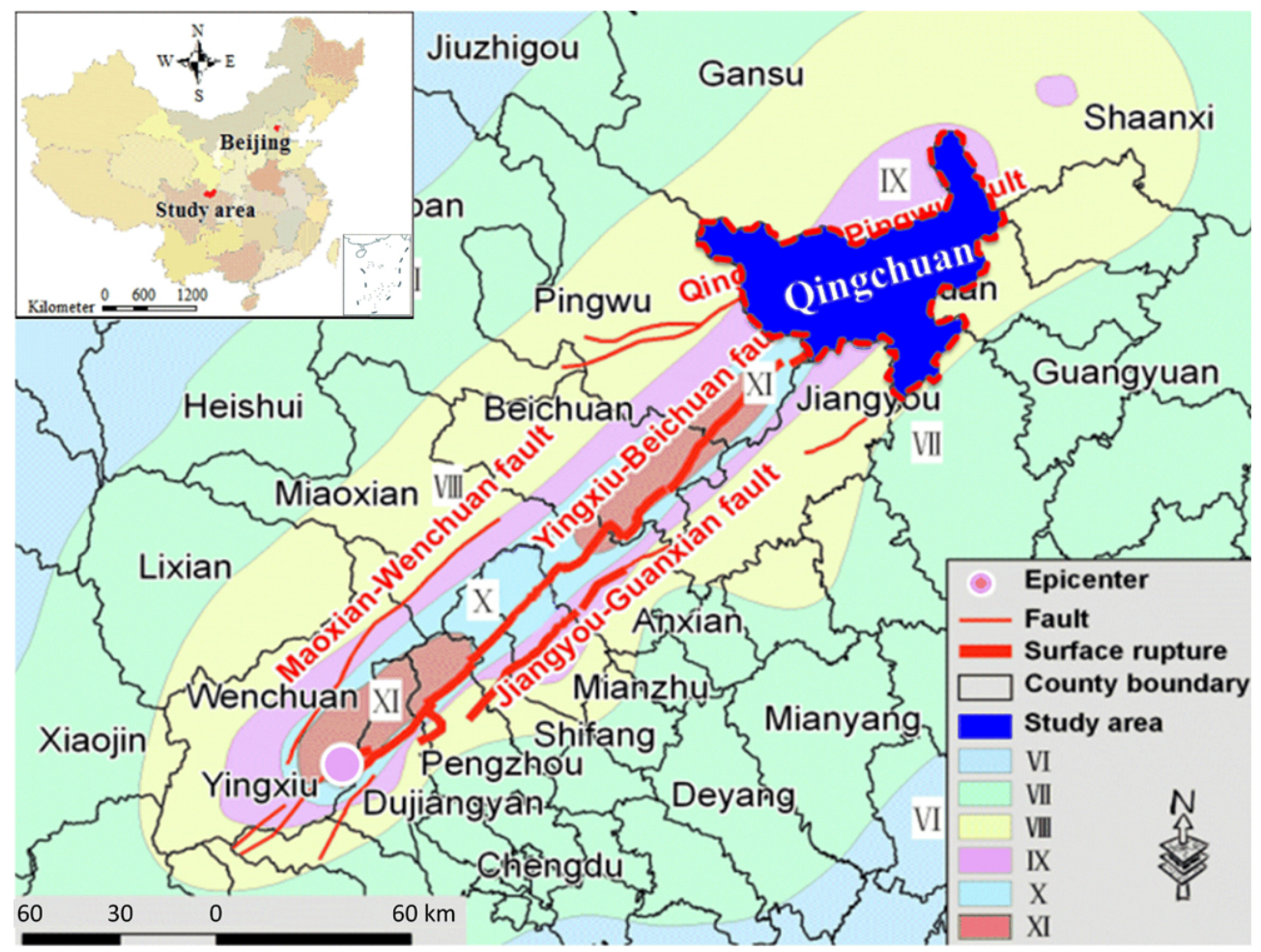

Fig. 1. Location of the study area, with China Seismic Intensity Scale of Wenchuan earthquake. Roman numerals VI-XI represent the earthquake magnitude contours.

area, almost all of the landslides that occurred before the Wenchuan earthquake were shallow landslides. Besides, according to the Qingchuan County Annals, about 20 earthquakes happened from 1956 to 2006, but no large earthquake occurred in this area. The earthquake with the highest magnitude was the one with magnitude 5 that occurred in 2005, and the others were with magnitude less than 3 . Therefore, the landslides that occurred before 12 May 2008 earthquake can be considered as rainfall-induced landslides. A total of 473 RILs have been recorded on the basis of field surveys. The EIL locations were identified from both field surveys and colour aerial photo interpretation (spatial resolution of $0.5 \mathrm{~m}$ ) over an area of $3271 \mathrm{~km}^{2}$, and a total of 885 EILs have been detected. The majority of them have a volume greater than $1000 \mathrm{~m}^{3}$, and 40 large landslides exceed a volume of $1000000 \mathrm{~m}^{3}$. Figure 2 is the regional lithological map of Qingchuan area and landslides location before and after the Wenchuan earthquake.

\section{Methodology}

This study aims to analyse the different impacts of rainfall and earthquake on landslides occurrence. Therefore, the following were especially concerned: (1) the variations between landslide spatial distribution and conditioning factors and (2) the variation of weight of each conditioning factor in the ANN prediction models. The first is implemented by comparing landslide frequency distribution for each factor by statistical analysis, and the second is implemented by training the neural network to calculate the contribution or importance of each factor for landslide occurrence. All the analyses are on the basis of slope-based mapping unit, which is relatively suited to landslide-related analysis, since landslides occur on slopes. This operation is performed automatically using Arc Hydro tool; the detail procedure was described in Xie et al. (2004). The controlling size was decided through adjusting the drainage area in this study. 55899 slope units were obtained in total at last.

\subsection{Conditioning factors selection}

The selection of conditioning factors greatly contributes to the landslide-related analysis. These factors include lithology, tectonics, geomorphology, topography, hydrology and so on (Kamp et al., 2008). The parameters utilized in this analysis (slope gradient, elevation, slope height, slope aspect, specific catchment area, lithology, distance to the fault and distance to the stream) are classic variables for landslide occurrence (for a review, see Carrara and Guzzetti, 1995; Soeters and van Westen, 1996; Dai and Lee, 2002).

All these factors were processed within ArcGIS. Slope gradient, elevation, slope height, and slope aspect were calculated using DEM. Specific catchment area, defined as 


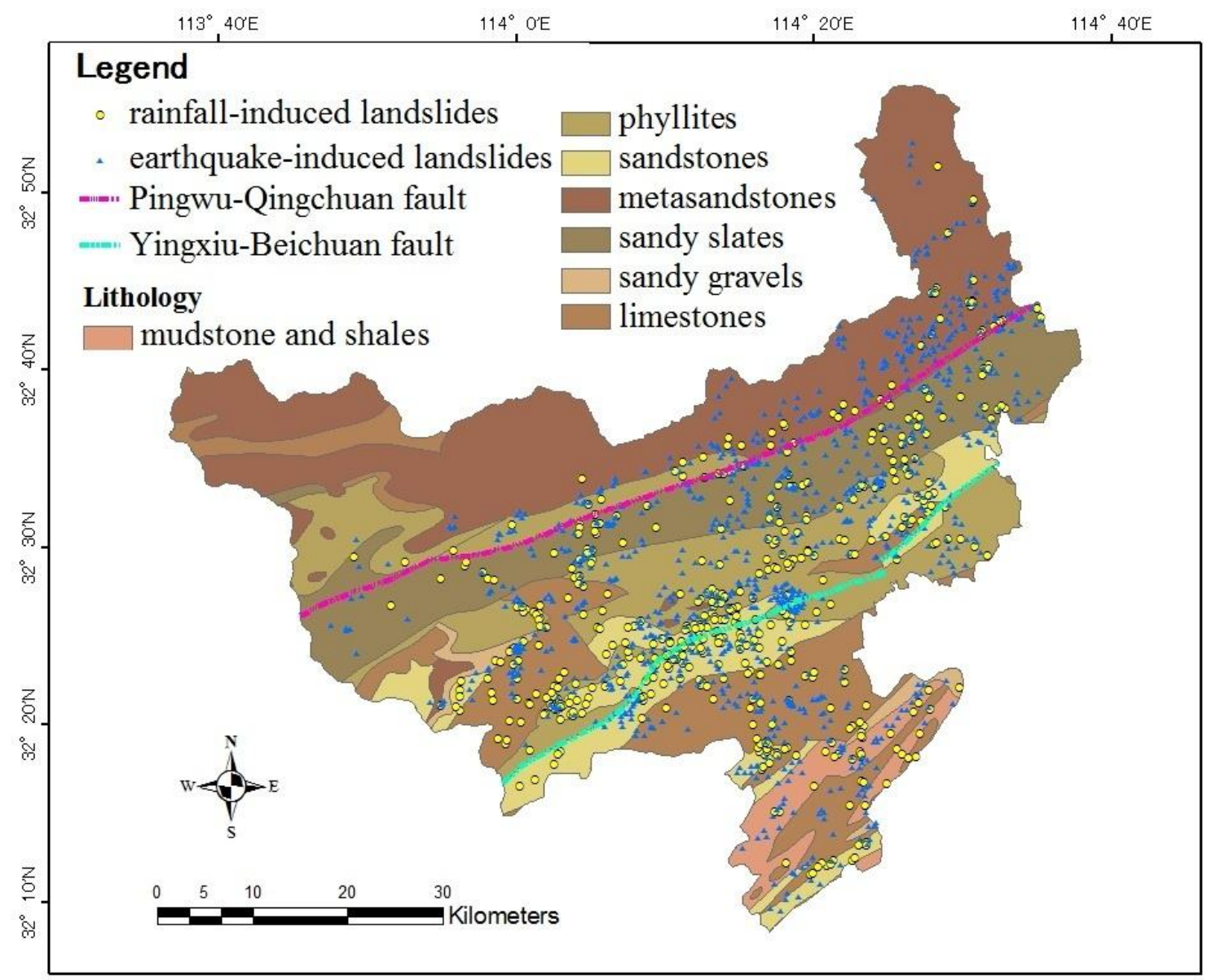

Fig. 2. Lithological map of Qingchuan area and locations of rainfall-induced landslides and earthquake-induced landslides.

the area of land upslope of a width of contour, divided by the contour width, is a commonly used quantity in hydrology to describe complex terrain for analyzing water flow on hill slopes (Tretkoff, 2011). Lithology map was digitized from the existing geological map. Distance to the fault was obtained by calculating the distance from landslides to the nearer fault of $\mathrm{F} 1$ or $\mathrm{F} 2$, which means, if the distances from one landslide to F1 and F2 are $5 \mathrm{~km}$ and $10 \mathrm{~km}$, then the distance from landslide to the nearer fault is $5 \mathrm{~km}$. Distance to the stream was made by applying a buffer to the stream network.

\subsection{Comparison of conditioning factors by landslide frequency analysis}

The relationship between landslides and each conditioning factor category has been examined as shown in Fig. 3. The number of the slope units in each category and the percentage of the category among the whole slopes are calculated. For each category, the percentage of the RILs and EILs among the total slopes in the same category is given as the landslide frequency.

\subsection{Landslide susceptibility analysis using Artificial Neural Network}

\subsubsection{Artificial Neural Network}

The Artificial Neural Network (ANN) program is a "computational mechanism able to acquire, represent, and compute a mapping from one multivariate space of information to another, given a set of data representing that mapping" (Garrett, 1994). The back-propagation (BP) algorithm is the most frequently used neural network training method. This algorithm is a multi-layered neural network, which consists of an input layer, hidden layers, and an output layer and trains the network until the target minimum error is achieved between the desired and actual output value of the network.

There are two stages involved in using neural network for multi-source classification: the training phase, in which the internal weights are adjusted, and the prediction phase. It is expected that the training data include all the data belonging to the problem domain. Certainly, this subset is used in the training stage of the model development to update the weights of the network. On the other hand, the test data 

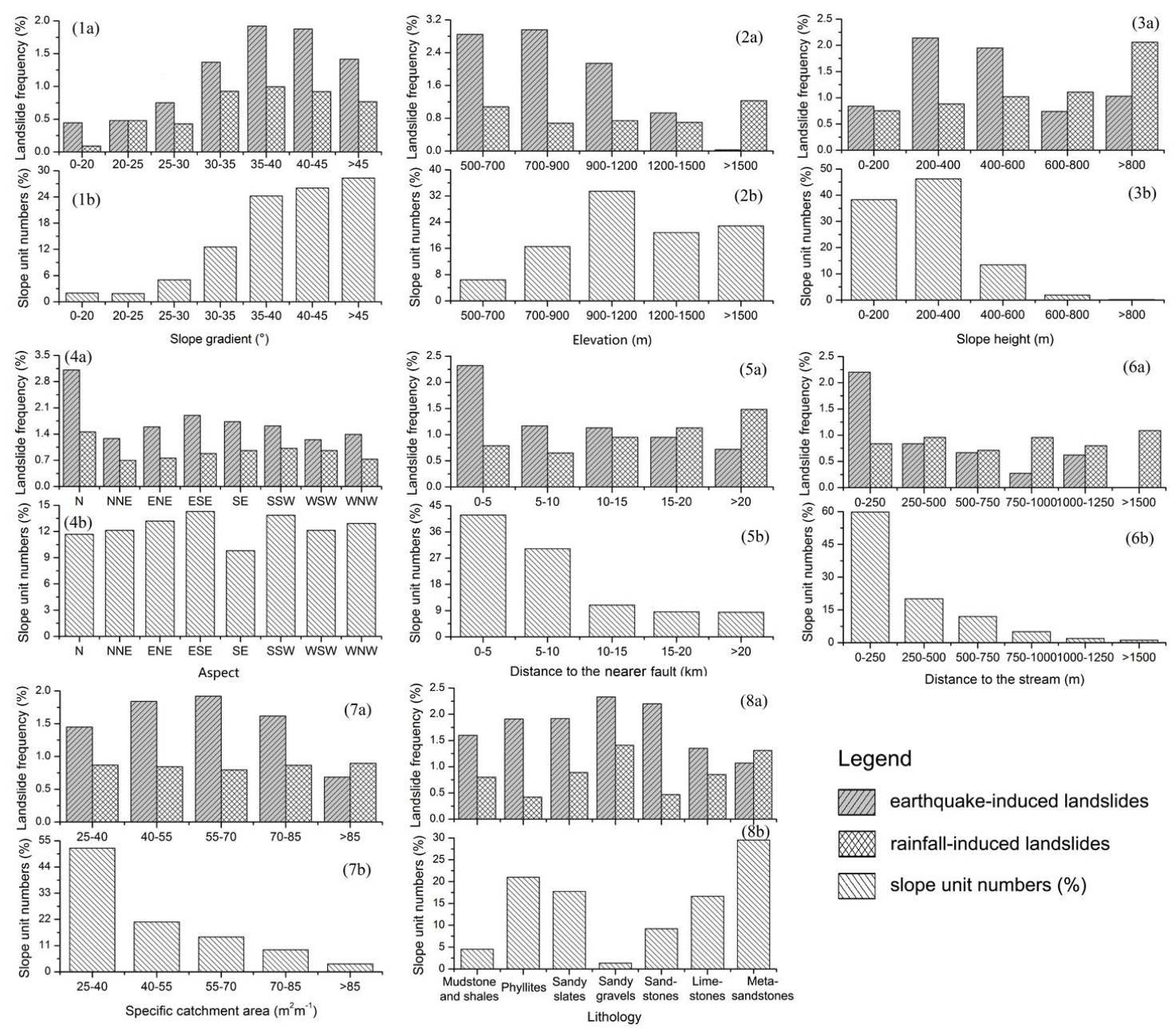

Legend

VIIA earthquake-induced landslides

rainfall-induced landslides

slope unit numbers $(\%)$

Fig. 3. Frequency distribution of the rainfall-induced landslides, earthquake-induced landslides and slope units of conditioning factors. The numbers (1-8) in the upper part of the diagrams indicate the eight conditioning factors; "a" stands for landslide frequency of RILs and EILs among the total slopes in the same category; "b" stands for the number of slope units in each category by percentage among the whole slopes.

should be different from those used in the training stage. The main purpose of this subset is to check the network performance using un-trained data and to confirm its accuracy. All the samples must be normalized since the variables are different in dimensions and not suitable for direct input for an ANN model.

\subsubsection{Training and prediction phase}

During the training phase, areas not affected by landslides were classified as "stable slope units", while areas affected by landslides were classified as "unstable slope units". The stable and unstable slope units were selected as training sites. Among the total 55899 slope units, about $70 \%$ of cases (39175 slope units, include 346 RILs and 597 EILs) were randomly selected as the training samples.

The neural network tool established within MATLAB software package by Hines (1997) was partially modified for landslide analysis. The typical back-propagation (BP) algorithm was applied to calculate the weights between the input and hidden layer, and between hidden layer and output layer, by modifying the number of hidden layers and the learning rate. All the input data in the ANN model were normalized in the range of 0.1 and 0.9 . The learning rate was set to 0.01 ; the initial weights were randomly selected between 0.1 and 0.3 . The number of epochs was set to 10000 , and the rootmean-square error (RMSE) value used for the stopping criterion was set to 0.01 .

The weight between the layers was acquired by training the neural network in order to calculate the contribution or importance of each conditioning factor. Different experiments were conducted. The best prediction model was established by adjusting its structure and the input layer factors. The performance of each model was evaluated by the training accuracy. Furthermore, in order to evaluate whether a general 


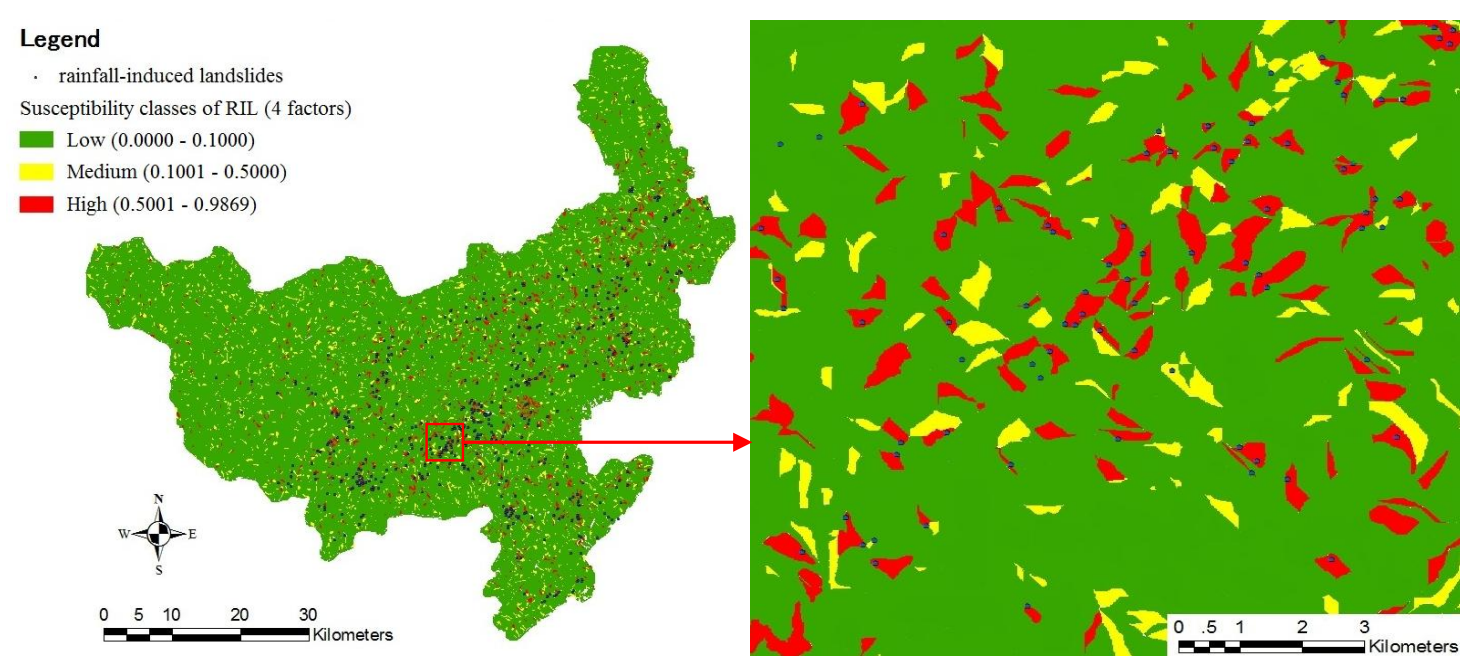

Fig. 4. Rainfall-induced landslide susceptibility map using Artificial Neutral Network. The right side figure is an expanded image of the red box range.

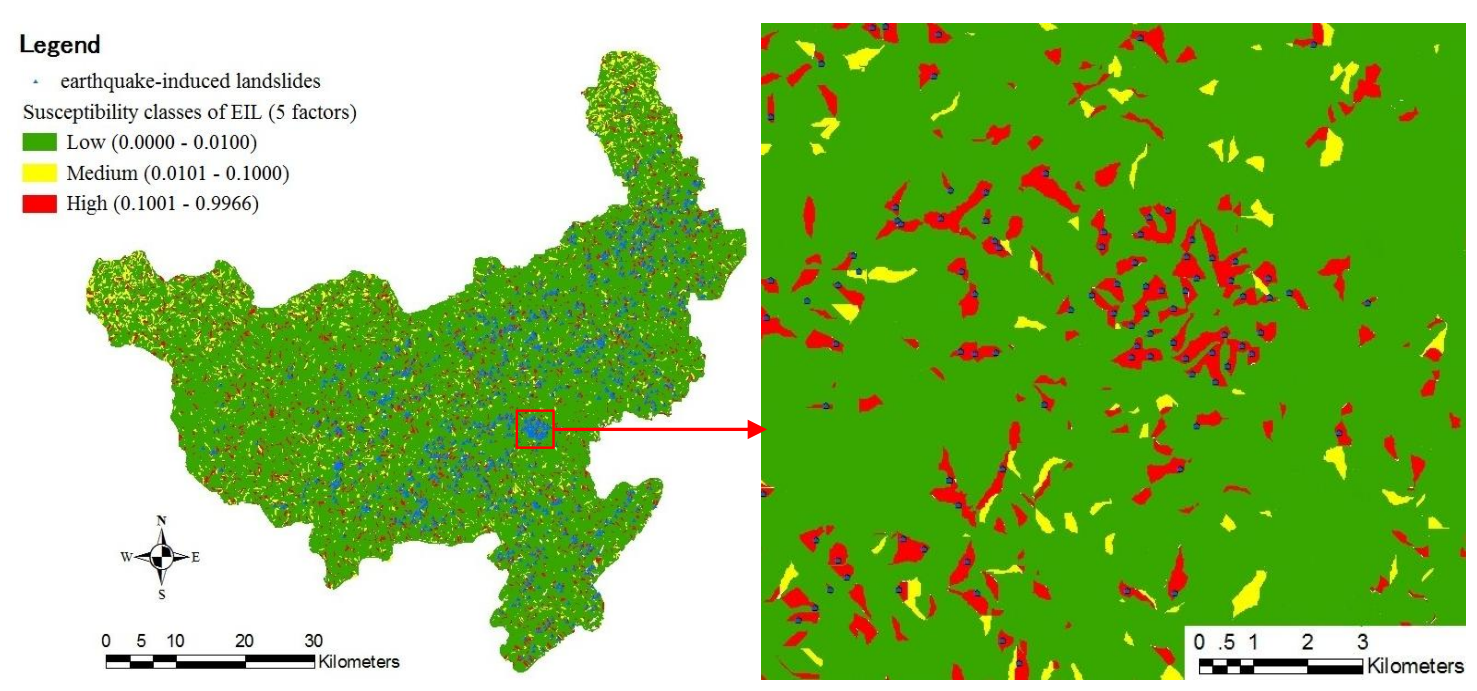

Fig. 5. Earthquake-induced landslide susceptibility map using Artificial Neutral Network. The right side figure is an expanded image of the red box range.

model can be established to suit both RIL and EIL, the EIL data were used to verify the RIL prediction model, while the RIL data were used to verify the EIL prediction model.

\subsubsection{Generation of landslide susceptibility maps}

Once the ANN prediction models were successfully trained and tested, they were used to categorize each slope unit of the whole dataset to produce landslide susceptibility maps. In other words, landslide susceptibility indexes were determined by the output layer values of ANN model directly. The values were between 0 and 1 , and they were converted to GIS raster data for each slope unit. Since the values were relatively concentrated, which meant almost all of the unstable area occurred with the indexes greater than 0.5 and almost all of the stable area occurred with the indexes smaller than 0.1 for RIL, the susceptibility values were classified into three categories (low, medium and high) for easy and visual interpretation. Using such values, the landslide susceptibility maps for RIL and EIL can be obtained.

\subsubsection{Validation of the trained ANN models and landslide susceptibility maps}

To validate whether the trained models are better or not, we used the method by comparing the prediction result and actual slope units free of or containing landslide (see Guzzetti et al., 2006). The remaining $30 \%$ of data (16 724 slope units, 
Table 1. Weight of each factor in different cases.

\begin{tabular}{lllllllll}
\hline \multirow{2}{*}{ Factor } & \multicolumn{3}{c}{ RIL } & \multicolumn{3}{c}{ EIL } \\
\cline { 2 - 9 } & Case 1 & Case 2 & Case 3 & Case 4 & Case 1 & Case 2 & Case 3 & Case 4 \\
\hline Slope gradient & 0.54 & 0.49 & 0.35 & 0.69 & 0.36 & 0.45 & 0.48 & 0.67 \\
\hline Slope elevation & 0.24 & 0.24 & 0.26 & 0.17 & 0.22 & 0.23 & 0.31 & 0.26 \\
Slope height & 0.14 & 0.19 & 0.31 & 0.14 & 0.15 & 0.15 & 0.11 & 0.07 \\
Slope aspect & 0.01 & $\times$ & $\times$ & $\times$ & 0.04 & $\times$ & $\times$ & $\times$ \\
Distance to the stream & 0.03 & 0.05 & 0.08 & $\times$ & 0.06 & 0.02 & $\times$ & $\times$ \\
Distance to the fault & 0.02 & 0.03 & $\times$ & $\times$ & 0.12 & 0.15 & 0.1 & $\times$ \\
Specific catchment area & 0.01 & $\times$ & $\times$ & $\times$ & 0.03 & $\times$ & $\times$ & $\times$ \\
Lithology & 0.01 & $\times$ & $\times$ & $\times$ & 0.02 & $\times$ & $\times$ & $\times$ \\
\hline Training accuracy & $91.82 \%$ & $92.30 \%$ & $93.90 \%$ & $88.87 \%$ & $95.05 \%$ & $96.39 \%$ & $96.14 \%$ & $91.96 \%$ \\
\hline Multi-layered network & $8 * 15 * 1$ & $5 * 3 * 1$ & $4 * 12 * 10 * 1$ & $3 * 3 * 1$ & $8 * 18 * 1$ & $5 * 3 * 5 * 1$ & $4 * 3 * 1$ & $3 * 3 * 1$ \\
\hline
\end{tabular}

including 127 RILs and 288 EILs) were used to validate the models.

However, this method only provides an estimation of ANN prediction model fit, because it does not provide a detailed description of the model performance of the different susceptibility classes (Chung and Fabbri, 1999). Success rate curve, which compares the total area of known landslides in each susceptibility class with the percentage area of the susceptibility class, was used to validate the produced maps. To compare the results quantitatively, the areas under the curve (AUC) were recalculated with the total area as 1 , which means perfect success rate. To obtain the relative ranks for the prediction results, the calculated landslide susceptibility indexes were subdivided into 10 classes in descending order, with accumulated $10 \%$ intervals.

\section{Results}

\subsection{Comparison between landslide spatial distribution and conditioning factors}

Comparison between landslide spatial distribution and conditioning factors was calculated from landslide frequency analysis based on slope unit. From the statistical analysis (Fig. 3), the following results can be found:

1. More than $90 \%$ of the slopes have a slope gradient larger than $20^{\circ}$. Both of the RILs and EILs occurred mainly in the slopes with gradients between $30^{\circ}$ to $45^{\circ}$;

2. RILs showed a slightly higher value in the slopes with the elevation more than $1500 \mathrm{~m}$; however, most of EILs occurred in the area with the elevations less than $1200 \mathrm{~m}$;
3. RILs showed a higher frequency in the area with slope height more than $800 \mathrm{~m}$, while EILs occurred mainly in the slopes with slope height from 200 to $400 \mathrm{~m}$;

4. RILs are evenly distributed in eight slope aspects. The number of EILs in the slopes in $\mathrm{N}$ direction is twice as much as the slopes in other directions;

5. The number of RILs is similar in each category of distance to the nearer fault of F1 or F2, while the number of EILs in the slopes with the distance to the nearer fault less than $0.5 \mathrm{~km}$ is twice as much as the slopes in other categories;

6. The number of EILs in the slopes with the distances to the stream less than $5 \mathrm{~km}$ is three times as much as the slopes in other categories, while the RILs numbers do not have so much difference;

7. There is no clear relationship between landslides and specific catchment area;

8. There is no clear relationship between landslides and lithology.

\subsection{Weight of each conditioning factor variation in the ANN prediction models}

As mentioned above, to calculate the contribution of each conditioning factor, 4 different cases were carried out. Case 1 used all of the 8 factors for building the ANN model; Case 2, 3 and 4 removed the lowest 3,4 and 5 factors by weight respectively. Table 1 summarizes the different ANN models for 
Table 2. Comparison between slope units classified as stable or unstable by the ANN model and slope units free of and containing RILs in the inventory map shown in Fig. 2.

\begin{tabular}{llll}
\hline & & \multicolumn{2}{c}{ Predicted groups (model) } \\
& & Stable & Unstable \\
\hline $\begin{array}{l}\text { Actual groups } \\
\text { (inventory) }\end{array}$ & Stable & $16378(98.68 \%)$ & $219(1.32 \%)$ \\
& Unstable & $47(37.01 \%)$ & $80(62.99 \%)$ \\
\hline
\end{tabular}

Table 3. Comparison between slope units classified as stable or unstable by the ANN model and slope units free of and containing EILs in the inventory map shown in Fig. 2.

\begin{tabular}{llll}
\hline & & \multicolumn{2}{c}{ Predicted groups (model) } \\
& & Stable & Unstable \\
\hline $\begin{array}{l}\text { Actual groups } \\
\text { (inventory) }\end{array}$ & Stable & $16433(99.98 \%)$ & $3(0.02 \%)$ \\
& Unstable & $0(0 \%)$ & $288(100 \%)$ \\
\hline
\end{tabular}

RIL and EIL, as well as the weight of the 8 factors obtained by applying BP neural network. It can be seen that slope gradient had the maximum weight value for both RIL and EIL, followed by slope elevation and height. Meanwhile, Case 3 for RIL model (which was built with four factors: slope gradient, elevation, slope height and distance to the stream) and Case 2 for EIL model (which was built with five factors: slope gradient, elevation, slope height, distance to the stream and distance to the nearer fault) presented the best training accuracy.

\subsection{Validation of the established ANN prediction models}

Tables 2 and 3 show the prediction results for RIL and EIL models. From the tables, it can be seen for RIL prediction model that 16458 of the 16724 mapping units were correctly classified. Regarding the 266 misclassified cases, 219 stable slopes were classified as unstable and 47 unstable slopes were attributed to the stable group by the ANN model. Further inspection of Table 2 reveals that the prediction model is more efficient in classifying stable slopes $(98.68 \%)$, and less efficient in classifying unstable slopes $(62.99 \%)$. For EIL prediction model, 16721 of the 16724 mapping units were correctly classified. There are only 3 misclassified cases, in which stable slopes were classified as unstable by the ANN model. Furthermore, the prediction model is very efficient in correctly classifying both stable $(99.98 \%)$ and unstable slopes $(100 \%)$.

\subsection{Validation of the landslide susceptibility maps}

Using the landslide susceptibility indexes determined from the output layer values of ANN models, the RIL and EIL

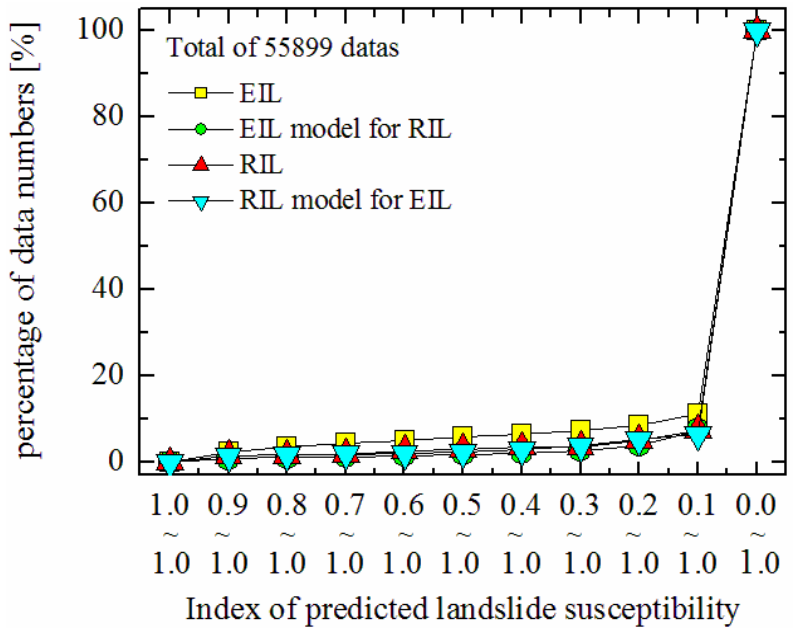

Fig. 6. Cumulative distribution of the susceptibility maps.

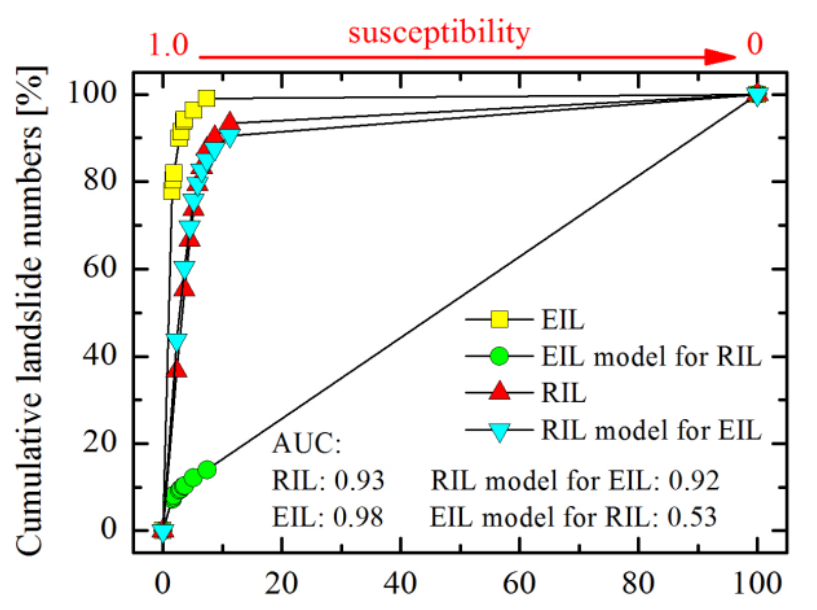

Cumulative area of predicted susceptibility [\%]

Fig. 7. Illustration of cumulative frequency diagram showing landslide susceptibility index rank ( $\mathrm{x}$-axis) occurring in cumulative percent of landslide occurrence (y-axis).

susceptibility maps were obtained (Figs. 4 and 5). Figure 6 shows the predicted indexes ranked from most to least susceptible (x-axis) against the percentage of all the slope units in the study area. Figure 7 shows the percentage of the study area ranked from most to least susceptible (x-axis) against the cumulative percentage of landslide area in each susceptibility class (y-axis).

Can et al. (2005) mentioned two rules for a spatially effective landslide susceptibility map: (i) observed landslide areas should coincide with the areas having high susceptibility values, and (ii) high susceptibility value should cover only small areas. From the lines, 90 to $100 \%$ (10\%) of EIL classification of the study area, where the landslide susceptibility index had a higher rank, accounts for $77.85 \%$ 


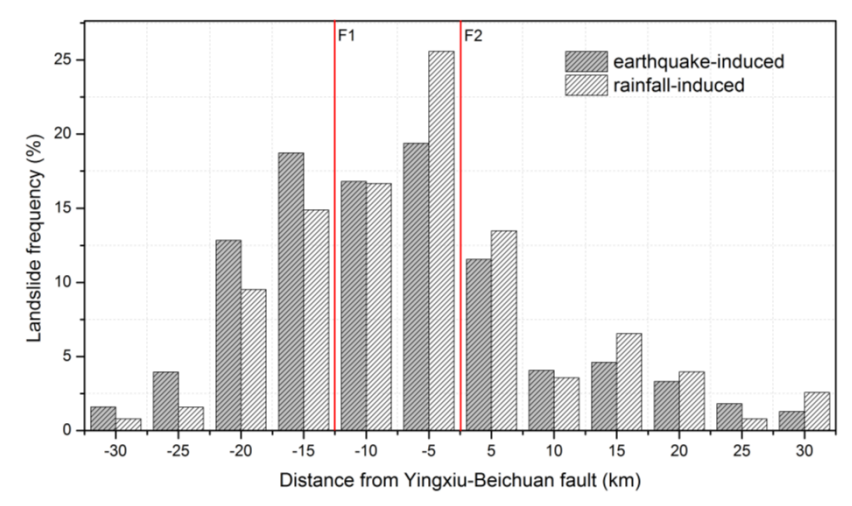

Fig. 8. The frequency histogram of landslides that occurred within every $5 \mathrm{~km}$ distance to the Yingxiu-Beichuan fault.

of all the landslides (Fig. 7), while covered only $2.31 \%$ of the total area (Fig. 6). Furthermore, 90 to $100 \%$ (10\%) of RIL classification of the study area predicted $36.64 \%$ of the landslides and the 50 to $60 \%(50 \%)$ classification of the study area predicted $79.35 \%$ of the landslides (Fig. 7), while covered only $1.76 \%$ of the entire area (Fig. 6). The calculated AUCs are showed in Fig. 7. The results for EIL were the best $(\mathrm{AUC}=0.98$ ), followed by the results for RIL and the prediction rate of EIL data using RIL model (AUC $=0.93,0.92$ respectively), while the results for the prediction rate of RIL data using EIL model were not so satisfactory (AUC $=0.53)$.

\section{Discussions}

The paper aims to analyse the different impacts of rainfall and Wenchuan earthquake on landslide occurrence. The relationships between landslide spatial distribution and conditioning factors were analysed from landslide frequency analysis. The weight of each conditioning factor variation was calculated in the ANN prediction models. In this part, we will discuss the analysis results carried out above in depth.

As to topographical factors, landslides are closely related to them and demonstrate certain general rules. The most important one is that both of RILs and EILs occurred mainly in the slopes with gradients less than $45^{\circ}$ and elevation lower than of $1200 \mathrm{~m}$. Based on field survey, the number of landslides in the area with high elevation (west and northeast area) is relatively less than the area with low elevation. Probably this can be explained with the following reason. The area with high elevation in Qingchuan County is the source of several great rivers, and the river valley is mainly $\mathrm{V}$-shaped and with shallow curve. In the middle and lower reaches, with the increase of catchment area and reduction of erosion basis, the shearing force of water flow is enhanced, which gives rise to the steep gorges in the downstream and provides premise conditions for the growth of geological disasters.
As to spatial distribution relationship between landslides and faults, distance to the nearer fault shown in Fig. 3 was obtained by calculating the distance from landslides to the nearer fault of F1 or F2. This method includes both of the two faults. As F2 is the seismogenic fault in 12 May 2008 earthquake, we also calculate the frequency histogram of landslides that occurred within every $5 \mathrm{~km}$ distance to the surface rupture along F2. In Fig. 8 the values of the coordinate on the horizontal axis stand for landslides distance to F2. The positive and negative values represent the distance from the landslide along footwall and hanging wall to F2 respectively. Meanwhile, the location of F1 is also annotated. It can be seen that the number of RILs is decreasing with the increase of distance to the causative fault F2, while the number of EILs has a slight higher value in the $10-15 \mathrm{~km}$ category on the hanging wall side. It shows that the 12 May 2008 earthquake influenced the landslide occurrence. An explanation for such a relationship (i.e. between landslide frequency and the distance to Yingxiu-Beichuan fault) is that PingwuQingchuan fault is affected by the Yingxiu-Beichuan fault, which leads to more EILs occur near F1.

As to lithology, landslides are more likely to happen in metasandstones and phyllites; however, no apparent relationship seems to exist between landslides and lithology due to the consideration that landslides in rock masses depend on their structural characteristics, mainly discontinuities in bedding and dip.

According to the weight of each conditioning factor calculated from ANN, either for RIL models or EIL ones, it can be pointed out that (1) the topography factors (slope gradient, slope elevation and slope height) have a dominate effect; (2) the lithology factor has no significant effect; and (3) the hydrological factor (distance to stream) has greater impact on RIL, while the earthquake factor (distance to fault) has greater impact on EIL. It is consistent with the landslide frequency histogram for each conditioning factor. This indicates that special topography, geological environment and the deep weathering rocks in this area make landslides occur easily under a trigger factor such as an earthquake or rainfall.

\section{Conclusions}

Landslides are one of the most serious natural hazards worldwide. Government and research institutions have worked for years to assess landslide hazard and to show its spatial distribution. In this study, RIL and EIL susceptibilities were assessed by means of GIS and ANN.

The relationships between landslide spatial distribution and conditioning factors were analysed from landslide frequency analysis, and the difference between RIL and EIL could be analysed in the aspects of topography, distances to fault or stream, and lithology. The advantage of ANN prediction models is that they objectively assign weights to different conditioning factors, as they involve a minimum of 
human interference. The weights provided us a good understanding of the conditioning factor contribution to landslide occurrence.

Success rate curves were created to validate the susceptibility maps. Verification results revealed that EIL (98\%) had higher success rate than RIL (93\%). However, the success rate of the EIL prediction data from trained RIL model can reach $92 \%$, while the success rate of RIL prediction data from trained EIL model can only reach $53 \%$.

The ANN models trained in this study, although not suitable for exportation to very different geomorphological settings, could be usefully applied in a large part of Sichuan Province, China, in which geological and geomorphological conditions are very similar to those of the study area. The results can be used as basic data to assist slope management and land-use planning.

Acknowledgements. This study has received financial support from Grants-in-Aid for Scientific Research (Scientific Research (B), 22310113, G. Chen) from Japan Society for the Promotion of Science and is supported by the Program for Basic Research of the Ministry of Science and Technology, China (2011FY110103). The supports are gratefully acknowledged.

Edited by: L. Franzi

Reviewed by: three anonymous referees

\section{References}

Ayalew, L., Kasahara, M., and Yamagishi, H.: The spatial correlation between earthquakes and landslides in Hokkaido (Japan), a GIS-based analysis of the past and the future, Landslides, doi:10.1007/s10346-011-0262-z, 2011.

Bai, S. B., Wang, J., Lu, G. N., Zhou, P. G., Hou, S. S., and Xu, S. N.: GIS-based logistic regression for landslide susceptibility apping of the Zhongxian segment in the Three Gorges area, China, Geomorphology 115, 23-31, 2010.

Can, T., Nefeslioglu, H. A., Gokceoglu, C., Sonmez, H., and Duman, T. Y.: Susceptibility assessments of shallow earthflows triggered by heavy rainfall at three subcatchments by logistic regression analyses, Geomorphology 72, 250-271, 2005.

Carrara, A. and Guzzetti, F.: Geographical Information Systems in Assessing Natural Hazards. Kluwer Academic Publishers, Dordrecht The Netherlands, 353, 1995.

Chang, K. T., Chiang, S. H., and Hsu, M. L.: Modeling typhoonand earthquake-induced landslides in a mountainous watershed using logistic regression, Geomorphology, 89, 335-347, 2007.

Chung, C. F. and Fabbri, A. G.: Probabilistic prediction models for landslide hazard mapping, Photogramm. Eng. Remote Sens., 65, 1389-1399, 1999.

Conoscenti, C., Maggio, C. D. and Rotigliano, E.: GIS analysis to assess landslide susceptibility in a fluvial basin of NW Sicily (Italy), Geomorphology, 94, 325-339, 2008.

Crozier, M. J.: Multiple-occurrence regional landslide events in New Zealand: Hazard management issues, Landslides, 2, 247256, doi:10.1007/s10346-005-0019-7, 2005.
Dahal, R. K. and Hasegawa, S.: Representative rainfall thresholds for landslides in the Nepal Himalaya, Geomorphology, 100, 429443, 2008.

Dai, F. C. and Lee, C. F.: Landslide characteristics and slope instability modeling using GIS, Lantau Island, Hong Kong, Geomorphology, 42, 213-228, 2002.

Ermini, L., Catani, F., and Casagli, N.: Artificial neural networks applied to landslide susceptibility assessment, Geomorphology, 66, 327-343, 2005.

Garrett, J.: Where and why artificial neural networks are applicable in civil engineering, J. Comput. Civil Eng., 8, 129-130, 1994.

Glade, T., Crozier, M. J., and Smith, P.: Applying Probability Determination to Refine Landslide-triggering Rainfall Thresholds Using an Empirical “Antecedent Daily Rainfall Model”, Pure Appl. Geophys., 157, 1059-1079, 2000.

Guzzetti, F., Reichenbach, P., Cardinali, M., Galli, M., and Ardizzone, F.: Probabilistic landslide hazard assessment at the basin scale, Geomorphology 72, 272-299, 2005.

Guzzetti, F., Reichenbach, P., Ardizzone, F., Cardinali, M., and Galli, M.: Estimating the quality of landslide susceptibility models, Geomorphology, 81, 166-184, 2006.

Hines, J. W.: Fuzzy and Neural Approaches in Engineering, Wiley, New York, 210, 1997.

Kamp, U., Growley, B. J., and Khattak, G. A.: GIS-Based Landslide Susceptibility Mapping for the 2005 Kashmir Earthquake Region, Geomorphology, 101, 631-642, 2008.

Kanungo, D. P., Arora, M. K., Sarkar, S., and Gupta, R. P.: A comparative study of conventional, ANN black box, fuzzy and combined neural and fuzzy weighting procedures for landslide susceptibility zonation in Darjeeling Himalayas, Eng. Geol., 85, 347-366, 2006.

Keefer, D. K.: Statistical analysis of an earthquake-induced landslide distribution of the 1989 Loma Prieta, California event, Eng. Geol. 58, 231-249, 2000.

Lee, C. T., Huang, J. F., Lee, K. L., Pan, K. L., Lin, M. L., and Dong, J. J.: Statistical approach to earthquake induced landslide susceptibility, Eng. Geol., 100, 43-58, 2008.

Lee, S. and Evangelista, D. G.: Earthquake-induced landslidesusceptibility mapping using an artificial neural network, Nat. Hazards Earth Syst. Sci., 6, 687-695, doi:10.5194/nhess-6-6872006, 2006.

Leonardo, E., Filipp, C. and Nicola, C.: Artificial Neural Networks applied to landslide susceptibility assessment, Geomorphology, 66, 327-343, 2005.

Lin, C. W., Liu, S. H., Lee, S. Y., and Liu, C. C.: Impacts of the Chi-Chi earthquake on subsequent rainfall induced landslides in central Taiwan, Eng. Geol., 86, 87-101, 2006.

Nefeslioglu, H. A., Gokceoglu, C., and Sonmez, H.: An assessment on the use of logistic regression and artificial neural networks with different sampling strategies for the preparation of landslide susceptibility maps, Eng. Geol., 97, 171-191, 2008.

Pradhan, B. and Lee, S.: Landslide susceptibility assessment and factor effect analysis: backpropagation artificial neural networks and their comparison with frequency ratio and bivariate logistic regression modeling, Environ. Modell. Softw., 25, 747-759, 2010.

Qi, S. W., Xu, Q., Lan, H. X., Zhang, B., and Liu, J. Y.: Spatial distribution analysis of landslides triggered by 2008.5.12 Wenchuan Earthquake, China”, Eng. Geol., 116, 95-108, 2010. 
Soeters, R. and van Westen, C. J.: Slope stability recognition, analysis, and zonation application of geographical information system to landslide hazard zonation, in: Landslides: Investigation and Mitigation. Sp.-Rep., edited by: Turner, A. K. and Schuster, R. L., 247, Transportation Research Board, National Research Council. National Academy Press, Washington, DC, 129-177, 1996.

Tang, C., Zhu, J., and Qi, X.: Landslide Hazard Assessment of the 2008 Wenchuan Earthquake: a case study in Beichuan Area, Canadian Geotech. J., 48, 128-145, 2011.

Tretkoff, E.: Calculating specific catchment area, Eos Trans. AGU, 92, 232, doi:10.1029/2011EO270019, 2011.

van Westen, C. J., van Asch, T. W. J., and Soeters, R.: Landslide hazard and risk zonation-why is it still so difficult?, Bull. Eng. Geol. Environ., 65, 167-184, 2006. van Westen, C. J., Castellanos, E., and Kuriakose, S. L.: Spatial data for landslide susceptibility, hazard, and vulnerability assessment: An overview, Eng. Geol. 102, 112-131, 2008.

Wieczorek, G. F.: Preparing a detailed landslide-inventory map for hazard evaluation and reduction, Bull. Assoc. Eng. Geol., 21, 337-342, 1984.

Xie, M. W., Esaki, T., and Zhou, G. Y.: GIS-Based Probabilistic Mapping of Landslide Hazard Using a Three-Dimensional Deterministic Model, Nat. Hazards, 33, 265-282, 2004.

Xu, Q., Zhang, S., and Li, W. L.: Spatial Distribution of Large-scale Landslides Induced by the 5.12 Wenchuan Earthquake, Science Press and Institute of Mountain Hazards and Environment, J. Mt. Sci. 8, 246-260, doi:10.1007/s11629-011-2105-8, 2011. 